\title{
A PROSPECTIVE STUDY OF TREATMENT OF INTERTROCHANTERIC FRACTURE FEMUR WITH TROCHANTERIC ENTRY NAIL IN ADULTS
}

\author{
Pereddy Somashekhara Reddy', M. Naveenchandar Reddy² \\ ${ }^{1}$ Associate Professor, Department of Orthopaedics, Apollo Institute of Medical Sciences and Research Center, \\ Apollo Health City, Hyderabad. \\ ${ }_{2}^{2}$ Senior Registrar, Department of Orthopaedics, Apollo Health City, Hyderabad.
}

\begin{abstract}
In the current series, we have done a randomized study of 50 cases of intertrochanteric fracture femur treated by minimally invasive intramedullary fracture fixation technique using trochanteric entry femoral nail. All the cases have been operated by senior Orthopaedic surgeons or have been operated under their guidance and supervision. All the cases have been followed up for a minimum period of 4-12 months. Average follow-up is 4 months. The results have been evaluated on the basis of Harris Hip Score. The results of this study have been compared to the I. B. Schipper series Gamma Nail and Proximal Femoral Nail in 424 cases of peritrochanteric fractures are done. The stable variety of intertrochanteric fractures (AO Type 31A.1) have good-to-excellent results in all the patients in the present series. The unstable variety (AO Type 31A.2 and A.3) in the current series have good to excellent results in $79 \%$ cases and fair results in $17.64 \%$ cases. However, various studies with extramedullary implants have shown only $59 \%$ good results. In the reverse oblique type of fracture as well as with subtrochanteric extension, Trochanteric entry femoral nail has given consistently good results, whereas studies with extramedullary implants have shown only $36 \%$ good results. So there is distinct advantage of intramedullary fixation in unstable varieties. The present study shows that trochanteric entry femoral nail has definite clear advantage over extramedullary implants in unstable fractures. At the same time, the implant that has good results in unstable fractures can always be used for stable fractures also.
\end{abstract}

\section{KEYWORDS}

Intertrochanteric Fracture, Recon Nail, Nailing, IT Fracture.

HOW TO CITE THIS ARTICLE: Reddy PS, Reddy MN. A prospective study of treatment of intertrochanteric fracture femur with trochanteric entry nail in adults. J Evolution Med Dent Sci 2016;5(13):576-582, DOI: 10.14260/jemds/2016/132

\section{INTRODUCTION}

Fractures of the proximal femur are more than ever an important challenge in the field of traumatology. ${ }^{1}$ These fractures are one of the most common fractures occurring in the elderly as emphasized by Smith Peterson, "Human beings come into this world through pelvis and leave this world through broken hips."

In this $21^{\text {st }}$ century, the focus has shifted from anatomical fixation to biological fixation of all fractures. Girdlestone warned, "There is inherent danger in the mechanical efficiency of our modern methods, danger lest the craftsmen forget that union cannot be imposed but may have to be encouraged. Where bone is a plant with its roots in soft tissues and when its vascular connections are damaged, it often requires not the technique of a cabinet maker, but the patient care and understanding of a Gardner."2

The goal is to obtain union of fracture in the most anatomical position compatible with maximal functional return of the extremity as early as possible. Because it is impossible to intervene surgically without adding further injury to the extremity, the technique chosen should minimize additional soft tissue damage and bone injury. An anatomical reduction obtained at the expense of total devascularisation of the fracture is not a well-planned or well-executed procedure.

Financial or Other, Competing Interest: None.

Submission 29-12-2015, Peer Review 22-01-2016,

Acceptance 30-01-2016, Published 15-02-2016.

Corresponding Author:

Pereddy Somashekhara Reddy,

Associate Professor,

Department of Orthopaedics,

AIMSR, Apollo Health City, Jubilee Hills,

Hyderabad.

E-mail: drpereddysr@gmail.com

DOI:10.14260/jemds/2016/132
One must always remember that any form of fixation is at best a splinting device with a definite lifespan and there is always a race between fracture union and failure of implant. 3,4

In the current century due to increased life expectancy and increased expectancy of a better quality of life, the Orthopaedic surgeons have a great challenge to face in treating proximal femoral fractures. The surgical management of these fractures has gone through array of implants and surgeries. Many questions have been raised regarding the configuration of a perfect fixation device. Until recently, most of these fractures were treated by a sliding hip screw system. ${ }^{5}$ Since this device performed less well in unstable proximal femoral fractures with high rates of failure, intramedullary fixation devices using minimal invasive fracture fixation technique have become increasingly popular.

A skilled surgeon can treat these fractures with any type of fixation device as long as he remembers that the fixation device will never make up for the surgical failures. Therefore, improvement in the treatment of proximal femoral fractures will be predominantly in the hands of the surgeons, rather than those of the implant industry. ${ }^{5}$

\section{AIMS AND OBJECTIVES}

Rationale of undertaking this project is to study

1. Management of intertrochanteric fracture femur with trochanteric entry femoral nail.

2. The advantages of minimally invasive intramedullary fracture fixation technique (Trochanteric entry femoral nail) in intertrochanteric fractures.

3. Evaluation of overall operative results of trochanteric entry femoral nail in intertrochanteric fractures.

4. Complications of the technique.

5. To set guidelines for the management of these fractures. 


\section{REVIEW OF LITERATURE}

In 1990, Halder introduced Gamma interlocking nail. ${ }^{6}$

In 1992, Bauongaertner demonstrated that indirect reduction and bridge plating (Biological osteosynthesis) leads to an overall improvement in the values for bone healing. The fracture gaps were bridged regularly and sequestra were rarely observed. 7

In 1992, a study on biomechanical evaluation using 10 cadaver femora was done by Rosendiun ST and Zuckerman JD. They applied $1800 \mathrm{~N}$ load over femora and strain determined in 2 and 4 part fractures. Motion of sliding screw and the nail was determined. The gamma nail transmitted fewer loads to calcar and no strain on posteromedial fragments of the bone; however, increasing compression was noted over proximal lateral cortex. The sliding hip screw showed increased calcar compression and decreased fracture stability. The insertion of distal locking screws did not change pattern of proximal femoral strain. The gamma nail imparts non-physiological strain to the proximal femur probably because of its internal stiffness. These strains may interfere with bone re-modeling and healing. ${ }^{8}$

In 1997, the AO/ASIF Research Institute introduced the proximal femoral nail (PFN, Mathys Medical Bettlach, Switzerland) for the treatment of peritrochanteric femoral fractures. It was designed to overcome implant related complications and facilitate the operative treatment of unstable peritrochanteric fractures. The proximal femoral nail uses two screws for fixation into the femoral head and neck. The larger screw is intended to carry the majority of the load. The smaller screw is inserted to provide rotational stability. ${ }^{9}$

In 1997, Huber SM, Heining SM and Euler E studied biomechanics of proximal femoral nail and showed significant reduction of distal stress and increase in overall stability compared with Gamma nail.10

In 1999, Simmermacher RK and Bosch AM did a study on the proximal femoral nail and their results showed a relatively low percent of complications and low incidence of implant failure as compared to gamma nail.11

In 2002, Saudan $M$ and Sadowski $C$ performed a randomized prospective study of 206 patients comparing dynamic hip screw and proximal femoral nail and stated the advantages of an intramedullary nail.12

In 2002, Al Yassari G, Jones JW, Al Lami M published the advantages of the AO proximal femoral nail for the treatment of unstable trochanteric fractures. ${ }^{13}$

In 2004, Schipper IB, Steyerberg EW and Kerver AJH did a randomized comparison of the gamma nail and proximal femoral nail of 424 cases. They concluded that the results of treatment of unstable trochanteric fractures were comparable for the PFN and Gamma nail. The pitfalls and the complications were similar and mainly surgeon or fracture related rather than implant related. 5

\section{MATERIALS AND METHODS}

The material will comprise of 50 adult patients diagnosed as intertrochanteric fracture femur with trochanteric entry nail during the period from August 2013 to February 2015. The patients will be regularly followed up and a prospective study and analysis will be carried out.

A thorough clinical examination including general, systemic and local examination will be conducted after a detailed history. An informed consent will be taken in the Proforma from each patient for participation in study.

All fractures will be classified according to AO classification. X-ray of the Hip in two views Antero-Posterior and Lateral will be taken.

\section{Inclusion Criterion}

1. Intertochanteric fracture femur.

2. Over 18 years old with skeletal maturity and consenting to participate.

3. Twenty one days or less between injury and surgery.

\section{Exclusion Criterion}

1. Open fractures.

2. Active infection in the area of the surgical approach.

3. Neurovascular injury requiring repair in the same limb.

4. Patients with non-union/previous failed fixations.

\section{SURGICAL TECHNIQUE}

Patient is kept in supine position on fracture table. Closed reduction is confirmed under image intensifier. If reduction is not possible in closed method, open reduction can be opted.

\section{STEPS}

1. Greater trochanter is palpated between thumb and index finger and a $3 \mathrm{~cm}$ incision is given $5 \mathrm{~cm}$ proximal to the tip of trochanter.

2. Entry point is made with bone awl over a tissue protector at the tip of greater trochanter in antero-posterior view and midpoint of greater trochanter in lateral view.

3. Guide wire is passed after confirming the reduction in both antero-posterior and lateral views. Serial reaming done.

4. Nail is introduced until sufficient depth is reached, which is confirmed under image intensifier.

5. Guide sleeve with obturator is introduced into the zig and skin incision is given and it is advanced till it touches the bone and then guide pin is drilled into the neck and head.

6. First distal guide pin is fixed followed by proximal guide pin. Distal guide pin is removed and then appropriate drill is used to drill and appropriate size lag screw is fixed under image intensifier.

7. Now proximal guide pin is removed then appropriate drill is used to drill and appropriate size lag screw is fixed under image intensifier.

8. Distal locking is done by free hand technique. 


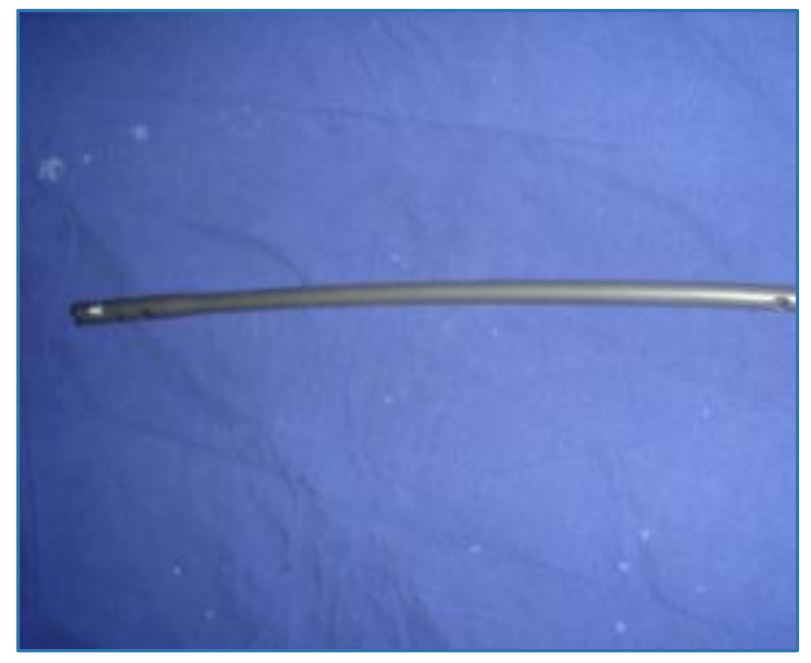

Trochanteric entry femoral nail

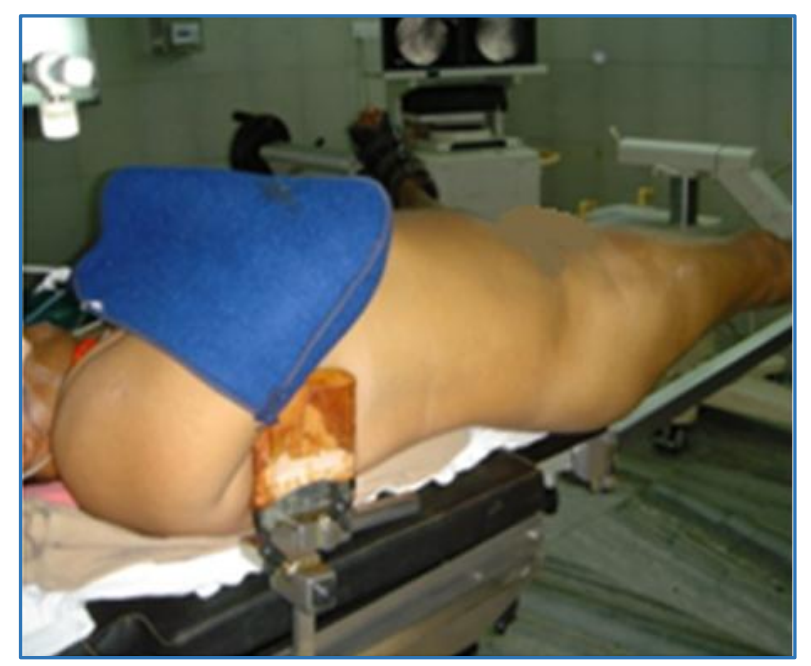

Position of the patient

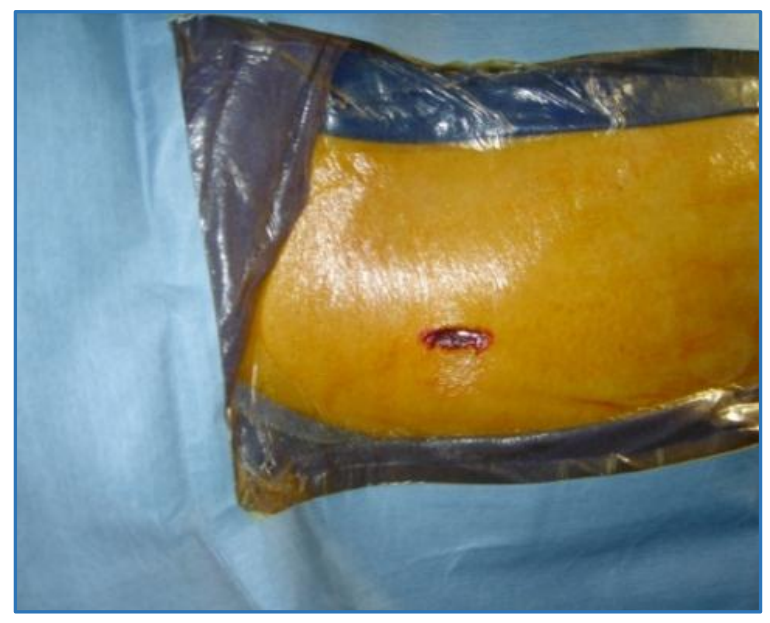

Skin incision

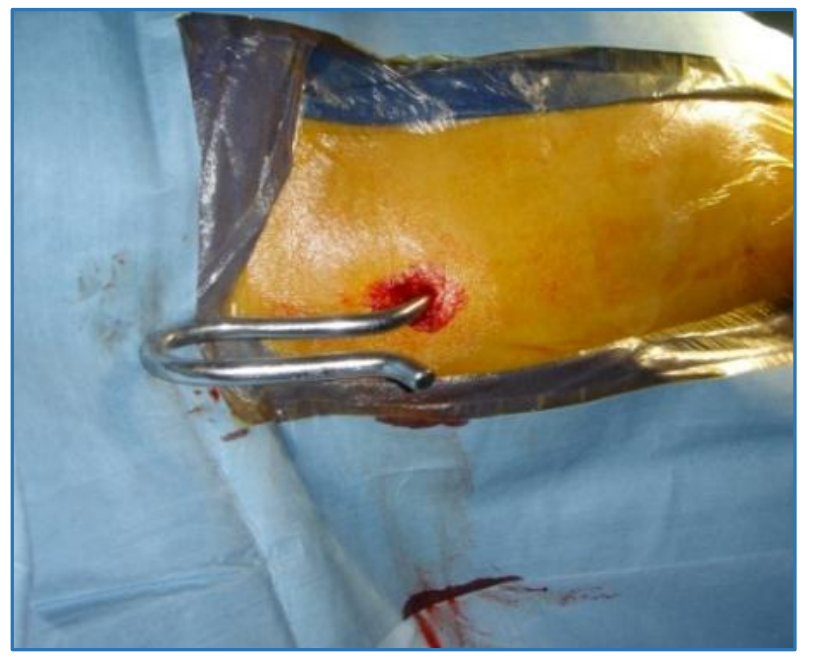

Entry point

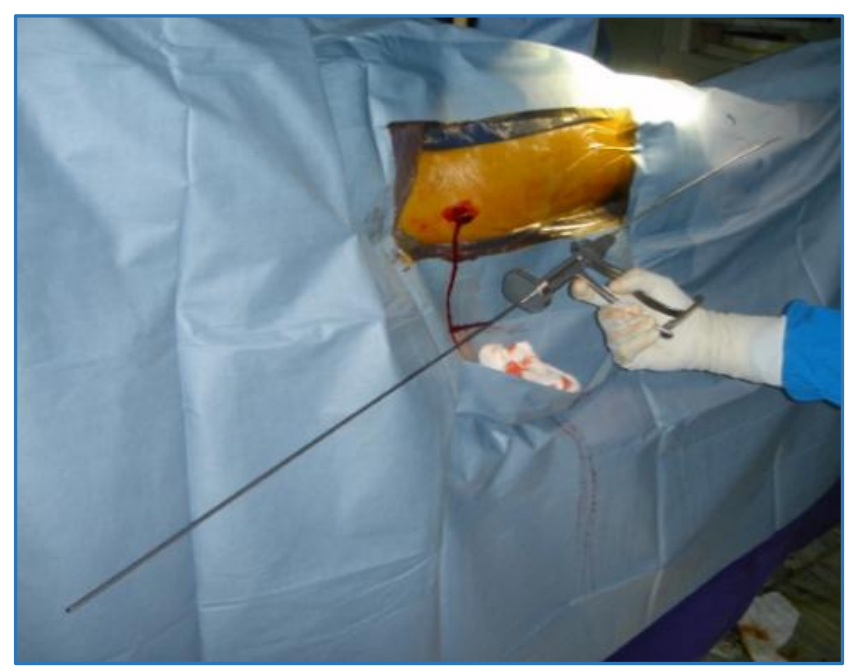

Guidewire placement

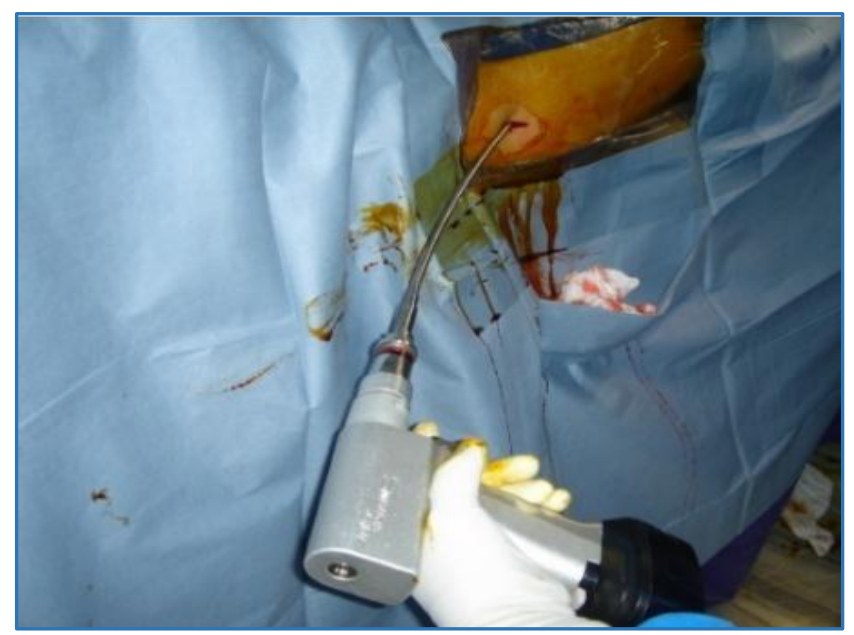

Reaming 


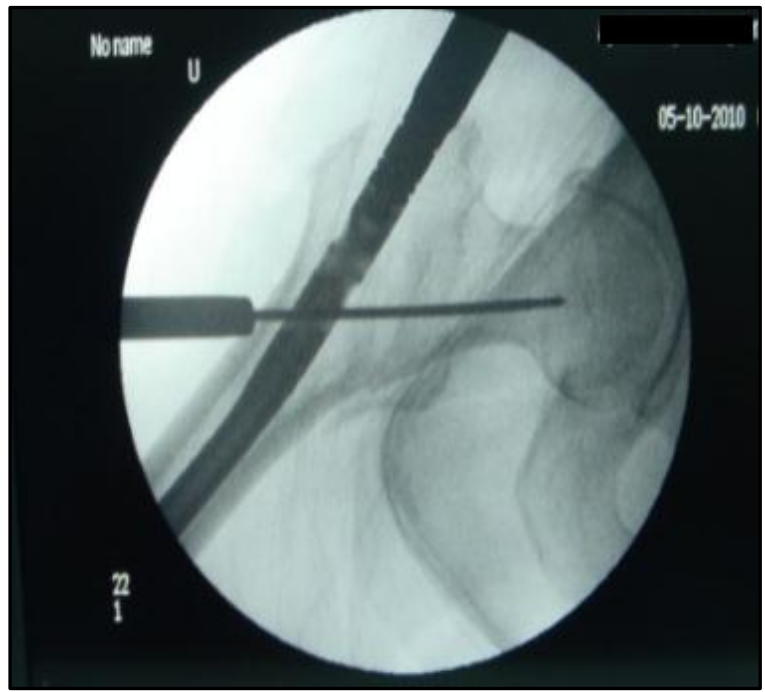

Nail in femur

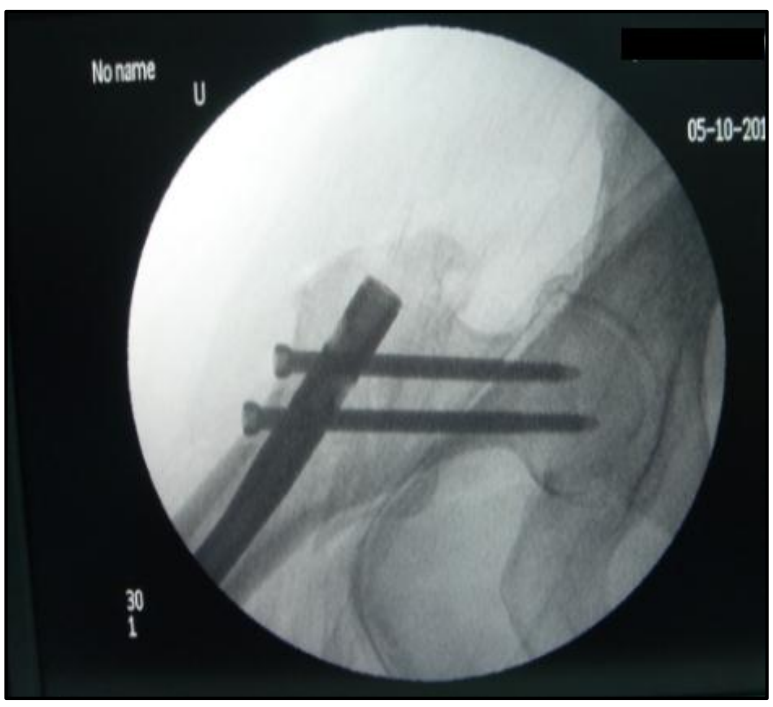

Proximal screws in AP view

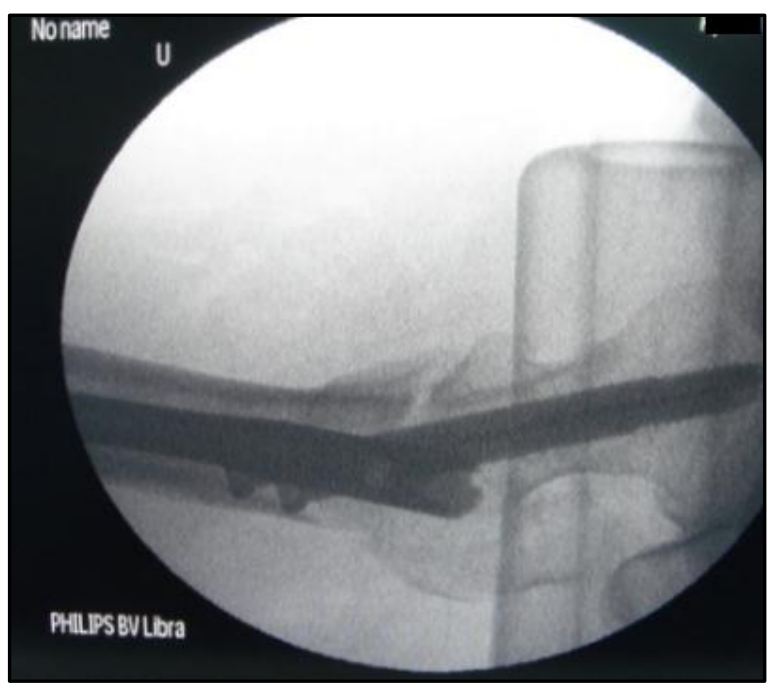

Proximal screws in lateral view

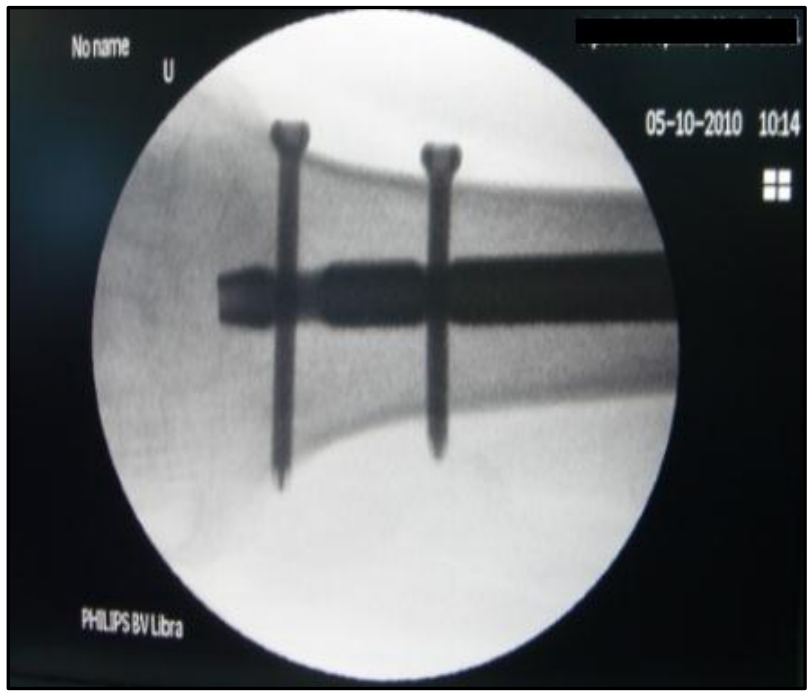

Distal screws in AP view

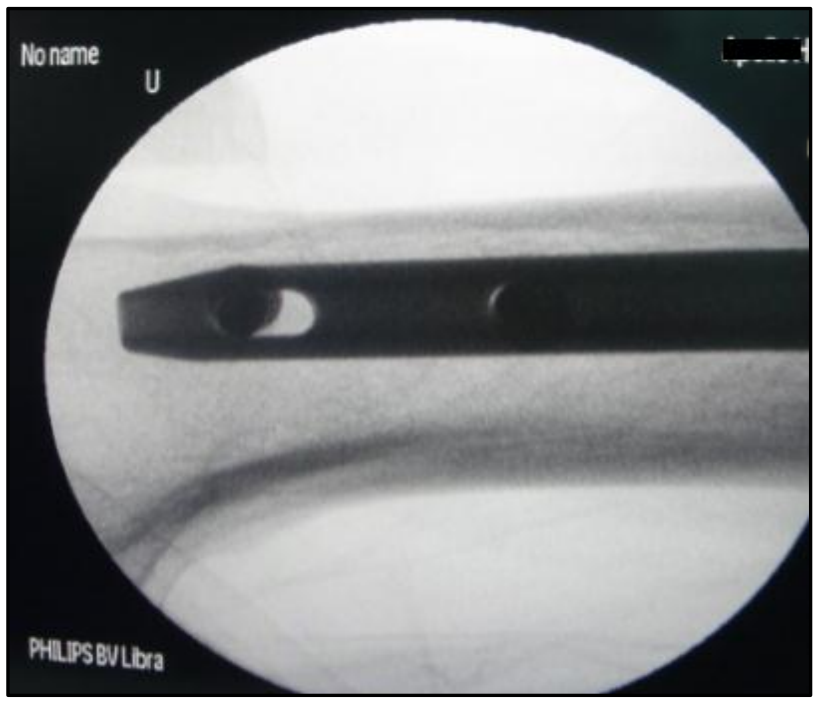

Distal screws in lateral view

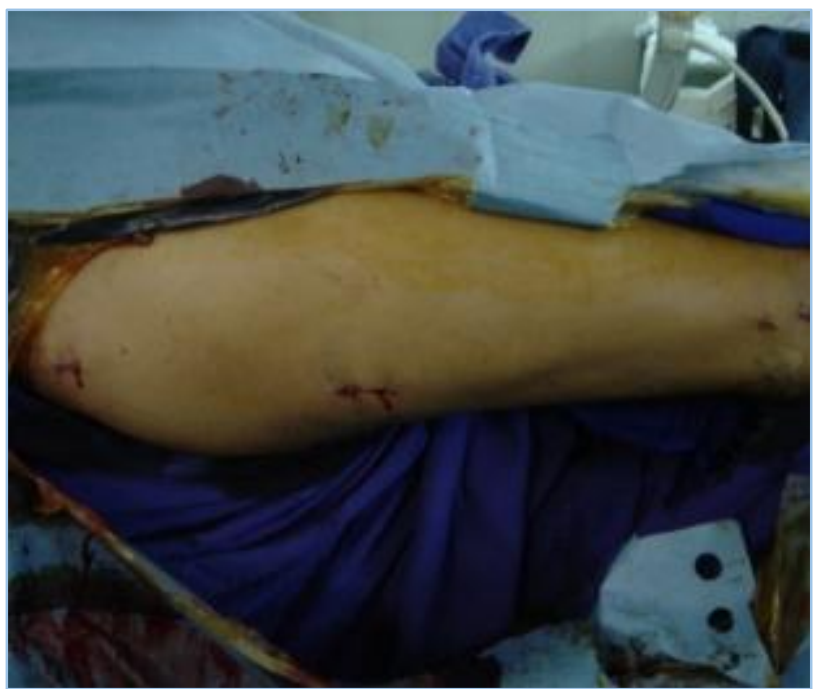

Skin closure 


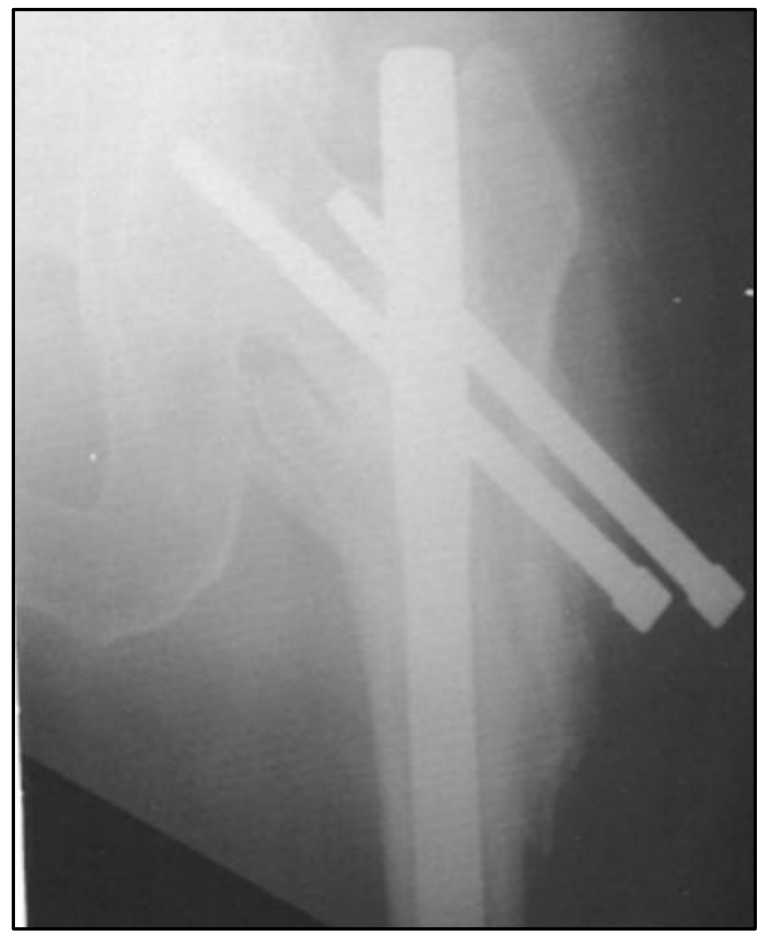

Screw back out

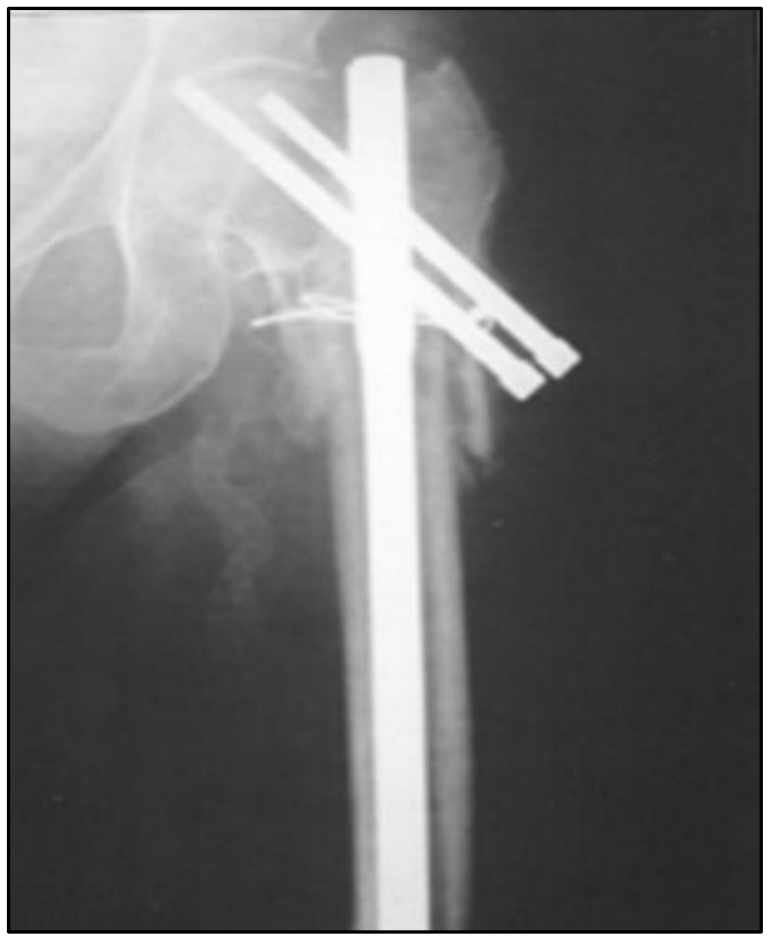

Proximal migration of screw

\section{OBSERVATIONS AND RESULTS}

In the current series, we have done a randomized study of 50 cases of intertrochanteric fracture femur treated by minimally invasive intramedullary fracture fixation technique using trochanteric entry femoral nail.

All the cases have been operated by senior orthopaedic surgeons or have been operated under their guidance and supervision. All the cases have been followed up for a minimum period of 4-12 months. Average follow-up is 4 months. The results have been evaluated on the basis of Harris Hip Score.
The results of this study have been compared to the I. B. Schipper series. ${ }^{5}$ Gamma Nail and Proximal Femoral Nail in 424 cases of peritrochanteric fractures are done.

Following are the observations of our study:

\section{AGE OF THE PATIENT}

\begin{tabular}{|c|c|c|}
\hline & Present series & I. B. Schipper series. \\
\hline $\begin{array}{l}\text { Mean Age } \\
\text { (In years) }\end{array}$ & 61.7 & 82.2 \\
\hline
\end{tabular}

\section{SEX}

In the present series, it is seen that the trochanteric fracture are more common in males. However, in I. B. Schipper series. ${ }^{5}$ females were more commonly injured.

\section{TYPE OF INJURY}

In males the fracture occurs commonly because of high velocity injury. In the present series, $51.85 \%$ males had sustained injury due to high velocity. But in females, they are more often caused by low velocity injury compared to their male counterparts. An $82.61 \%$ females had sustained injury because of a low velocity injury.

Average age in males is 58.4 years and average age in female patient is 65.6 years. This also signifies that female patients are older than male patients and so were more predisposed lo low velocity trauma secondary to osteoporosis.

\section{INJURY-OPERATION INTERVAL}

Early operational treatment reduces both mortality and mobility, giving best chance of early independence and reducing risk of prolonged bed rest. The average injury operation interval in the current series was 2 days. The interval was significantly increased in the patients with other associated injuries or with pre-existing illness.

\section{PRE-EXISTING ILLNESS AND MORTALITY}

\begin{tabular}{|c|c|c|}
\hline Comorbidities & Present Series & Percentage \\
\hline Hypertension/Diabetes & 10 & $20 \%$ \\
\hline Ischaemic heart disease & 5 & $10 \%$ \\
\hline Mortality within 4 weeks & 1 & $2 \%$ \\
\hline
\end{tabular}

In the current series, almost $30 \%$ of patients had medical comorbidities, one patient died 4 weeks postoperative period.

\section{TYPE OF FRACTURE}

\begin{tabular}{|c|c|c|c|}
\hline $\begin{array}{c}\text { Fracture } \\
\text { Type }\end{array}$ & $\begin{array}{c}\text { Present } \\
\text { Series }\end{array}$ & Percentage & $\begin{array}{c}\text { I. B. Schipper } \\
\text { Series. }\end{array}$ \\
\hline Stable & 16 & $32 \%$ & $37 \%$ \\
\hline Unstable & 34 & $68 \%$ & $63 \%$ \\
\hline Total & 50 & $100 \%$ & $100 \%$ \\
\hline
\end{tabular}

\section{PEROPERATIVE FACTORS}

\begin{tabular}{|c|c|c|}
\hline & $\begin{array}{c}\text { Present } \\
\text { Series }\end{array}$ & $\begin{array}{c}\text { I. B. Schipper } \\
\text { Series. }\end{array}$ \\
\hline $\begin{array}{c}\text { Average operating } \\
\text { time }\end{array}$ & 70 & 60 \\
\hline $\begin{array}{c}\text { Average skin } \\
\text { incision }\end{array}$ & 5 & 6.5 \\
\hline Average blood loss & 50 & 220 \\
\hline
\end{tabular}


However, operating time may differ for different surgeons and according to complexity of fractures.

\section{FRACTURE UNION}

The average full weight bearing time in the present series is 2.3 months and the average radiological union time is 3 months. It is comparable to the I. B. Schipper series. ${ }^{5}$ where weight bearing time is 2.5 months and radiological union time is 4 months.

\section{POSTOPERATIVE COMPLICATIONS}

\section{SURGICAL}

\begin{tabular}{|c|c|c|c|}
\hline Complications & $\begin{array}{c}\text { Present } \\
\text { Series }\end{array}$ & Percentage & $\begin{array}{c}\text { I. B. } \\
\text { Schipper } \\
\text { Series. }\end{array}$ \\
\hline $\begin{array}{c}\text { Superficial } \\
\text { infections }\end{array}$ & 1 & $2 \%$ & $4.1 \%$ \\
\hline Deep infections & 1 & $2 \%$ & $2.5 \%$ \\
\hline Pressure sores & None & - & $8.5 \%$ \\
\hline
\end{tabular}

\section{IMPLANT RELATED COMPLICATIONS}

\begin{tabular}{|c|c|c|c|}
\hline Complications & $\begin{array}{c}\text { Present } \\
\text { Series }\end{array}$ & Percentage & $\begin{array}{c}\text { I. B. } \\
\text { Schipper } \\
\text { Series. }\end{array}$ \\
\hline Cut out of screws & 2 & $4 \%$ & $6.9 \%$ \\
\hline $\begin{array}{c}\text { Lateral migration } \\
\text { of hip screw }\end{array}$ & None & - & $7.6 \%$ \\
\hline Medial protrusion & None & - & $1 \%$ \\
\hline Shaft fracture & None & - & $2 \%$ \\
\hline
\end{tabular}

\section{ASSESSMENTS AT FINAL FOLLOWUP PAIN}

In our $70 \%$ of cases had no pain, $16 \%$ of patients had slight pain occasionally which required no treatment; $10 \%$ cases had mild pain which was relieved by analgesics on and off. Only $4 \%$ cases had moderate pain, which also relieved by medications.

\section{LIMP}

In the current series $78 \%$ cases had no limp; $18 \%$ cases had slight limp which was because of occasional pain. Only $4 \%$ cases had moderate limp, which was primarily because of shortening.

\section{WALKING ABILITY (SUPPORT)}

In the current series $62 \%$ cases did not require any support for walking; $28 \%$ cases required cane for long walks, whereas $10 \%$ cases required cane most of the time. The requirement of cane is primarily because of old age of the patients and associated osteoarthritis.

\section{DISTANCE WALKED}

In the current series, $64 \%$ cases had no problem in walking any amount of distance. However, $36 \%$ cases had walking ability up to 6 blocks only. This limitation is commonly seen in geriatric age group.

\section{STAIRS}

In our series $64 \%$ cases could climb stairs without using a railing, whereas $36 \%$ cases required railing for climbing stairs. Difficulty in climbing stairs was commonly seen in geriatric age group.

\section{SQUATTING}

Squatting was possible with ease in $62 \%$ cases with difficulty in $28 \%$ cases; $10 \%$ of patients were not able to squat. The difficulty in squatting was primarily seen in old age patients with osteoarthritis of knee.

\section{SITTING CROSS LEGGED}

Sitting cross legged was possible with ease in $64 \%$ cases and with difficulty in $28 \%$ cases; $8 \%$ of patients were not able to sit cross legged. This was also primarily due to osteoarthritis knee.

\section{LIMB LENGTH DISCREPANCY}

Out of 50 cases 41 cases had no shortening, 6 cases had shortening of less than $2 \mathrm{cms}$, which did not require any treatment; 3 cases had shortening of more than $2 \mathrm{cms}$ which were treated with shoe raise.

\section{OVERALL RESULTS BASED ON FRACTURE TYPE}

Based on the $\mathrm{AO}$ classification, out of 16 patients with $\mathrm{A} 1$ type of fractures, 15 patients had good-to-excellent results. Only 1 patient had poor result because of infection. Out of 34 patients with unstable fracture, 27 cases had good-to-excellent results, 6 cases had fair result and 1 case had poor result.

\section{DISCUSSION}

We have treated 50 patients of intertrochanteric fracture femur (Extracapsular type) by minimal invasive fracture fixation technique using trochanteric entry femoral nail between August 2013 to February 2015. A prospective randomized study was done for evaluation of results of this technique.

All the cases were classified according to the $\mathrm{AO}$ classification, which is the most accepted classification all over the world. All the surgeries either were done by Sr. Surgeons themselves or were done under their guidance. All the patients were followed up for an average period of four months. The results are evaluated on the basis of Harris Hip Score. This system is slightly modified according to the needs of the Indian patients, i.e. in place of "Put on shoes and socks," we have used "Squatting" and in place of sitting we have used "sitting cross legged." The results of this study have been compared to the I. B. Schipper series. ${ }^{5}$ where comparison of Gamma Nail and Proximal Femoral Nail in 424 cases of peritrochanteric fractures are done.

The preoperative factors that were taken into consideration were average operating time and blood loss. The average operating time in our series was 70 minutes, which is more than that of I.B. Schipper series. ${ }^{5}$ ( 60 minutes). However, operative time may differ for different surgeons and according to complexity of the fracture. The average blood loss in our series was $50 \mathrm{ml}$, which was less than that of I.B. Schipper series. ${ }^{5}(130 \mathrm{ml})$.

The average time of full weight bearing in the present series was 2.3 months and the average time of radiological union was 4 months, whereas in I.B. Schipper series. ${ }^{5}$ it was approximately 2.5 months and 4 months respectively. The full weight bearing time was less in stable fractures as compared to unstable fractures. In both the series, the weight bearing time is less as compared to other studies of extramedullary implants, which is primarily due to biomechanical properties of the nail. 
In the current series only 1 patient $(2 \%)$ had developed superficial infection, which is comparable to any other international study ( $4.1 \%$ in I.B. Schipper series.5). As far as deep infection is considered, 1 case $(2 \%)$ developed deep infection (2.5\% in I.B. Schipper series. $\left.{ }^{5}\right)$.

In our series, 2 cases (4\%) had cut out of hip screw. In one, it happened after premature weight bearing, whereas in I.B. Schipper series. $54.1 \%$ cases had cut out.

We had no cases of the shaft fracture as well as pressure sores, which was present in $2 \%$ and $8.5 \%$ cases respectively in I.B. Schipper series. ${ }^{5}$

In the present series, out of 50 cases, 16 cases had stable fracture and 34 patients had unstable type fracture. All the cases were treated by intramedullary fracture fixation techniques (Trochanteric entry femoral nail).

We have used the Harris hip score for evaluation of results. In the stable varieties, 15 patients in our series had good-to-excellent results. Only 1 case had poor result.

In the unstable varieties, out of 34 cases we got good-toexcellent results in 27 cases, fair results in 6 cases and poor results in 1 case.

None of the implant gives $100 \%$ immunity to complications for a particular fracture, but the implant which can avoid maximum complication is considered as gold standard for a particular fracture. The results of our study have shown that the ideal implant for unstable proximal femoral fractures (Extracapsular type) is the Trochanteric entry femoral nail. The technique is equally competent, as is the extramedullary fracture fixation technique in stable fractures.

\section{CONCLUSION}

- The present study includes 50 operated cases of intertrochanteric femoral fractures (extracapsular type). This is a prospective randomized study of minimal invasive fracture fixation technique by intramedullary implants (Trochanteric entry femoral nail) with an average follow-up of 4 months.

- In the present series, majority of patients belongs to geriatric age group and the injury sustained is because of low velocity trauma, which is mainly because of osteoporosis as well as increased expectancy of life in our country.

- The stable variety of intertrochanteric fractures (AO Type 31A.1) have good-to-excellent results in all the patients in the present series.

- The unstable variety (AO Type 31A.2 and A.3) in the current series have good-to-excellent results in $79 \%$ cases and fair results in $17.64 \%$ cases. However, various studies with extramedullary implants have shown only 59\% good results. In the reverse oblique type of fracture as well as with subtrochanteric extension, trochanteric entry femoral nail has given consistently good results, whereas studies with extramedullary implants have shown only $36 \%$ good results. So there is distinct advantage of intramedullary fixation in unstable varieties.

- The average blood loss is $50 \mathrm{ml}$ approximately and average operating time is 70 minutes. Being a closed procedure, minimal amount of blood loss and soft tissue damage occurs, which has an overall good prognosis.

- The implant related complications are minimal in the current study because of biomechanical advantages of the trochanteric entry femoral nail.

- The overall infection rate is minimal in the current series because of small incision and less soft tissue damage.

The present study shows that trochanteric entry femoral nail has definite clear advantage over extramedullary implants in unstable fractures. At the same time, the implant that has good results in unstable fractures can always be used for stable fractures also.

\section{BIBLIOGRAPHY}

1. Valverde JA. Use of gamma nail in treatment of fractures of proximal femur. CORR 1998;350:56-61.

2. Girdlestone GR. The treatment of fracture in the light of their ischemic complications. JBJS 1932;14:755.

3. Cornell CN, Lan JM. Newer factors in fracture healing. Clin Orthop 1992; 277:297.

4. Frost HM. The biology of fracture healing. An overview for clinician. Clin Orthop 1989;248:283.

5. Schipper IB, et al. Treatment of unstable trochanteric fractures. JBJS 2004;86B:86-94.

6. Halder SC. The Gamma nail for peritrochanteric fractures. JBJS(Br) 1992;72:340-344.

7. Bauongaertner $\mathrm{MR}$, et al. Intramedullary vs extra medullary fixation for the intertrochanteric hip fractures. CORR 1998;348:87-94.

8. Rosendiun ST, et al. Biomechanical evaluation of gamma nail. JBJS 1992;74:352-357.

9. Schipper IB, et al. Biomechanical evaluation of proximal femoral nail. CORR 2002;405:277-286.

10. Huber SM, Heining. Peritrochanteric fracture fixation, photoelastic stress measurement company DHS, Gamma nail and PFN. JBJS (Br) 1997;79:166.

11. Simmermacher RK, Bosch AM. The AO proximal femoral nail - A new device for unstable proximal femoral fracture. Injury 1999;30:327-332.

12. Saudan M, Sadowski C, et al. Peritrochanteric fractures. Is there an advantage of intra-medullary nail? J Orthop Trauma 2002;16:386-393.

13. Al Yassari G, Jones JW. The AO/ASIF proximal femoral nail for treatment of unstable trochanteric fractures. Injury 2002;33:395-399. 